\title{
Fangchinoline Induces Apoptosis, Autophagy and Energetic Impairment in Bladder Cancer
}

\author{
Bo Fan Xiaoyu Zhang Yongliang Ma Aili Zhang \\ Department of Urology, The Fourth Hospital of Hebei Medical University, Shijiazhuang, Hebei, P.R. \\ China
}

\section{Key Words}

Bladder cancer $•$ Fangchinoline $\bullet$ Autophagy $•$ Apoptosis $\bullet$ Proliferation

\begin{abstract}
Abatract
Background/Aims: Tetrandrine and Fangchinoline ( $F(n)$ are two natural products that are found in Stephania tetrandra. Tetrandrine is a known anti-bladder cancer compound, but the effects of Fcn on bladder cancer have been previously unclear. In the present study, we focused on the anti-tumor effects of Fcn on bladder cancer. Methods and Results: We treated T24 and 5637 bladder cancer cell lines with Fcn in vitro. We observed that Fcn inhibited the viability of bladder cancer cells in a concentration-dependent manner. The expression of PCNA, a biomarker of proliferation, was down-regulated. Fcn treatment induced both apoptosis and autophagy in bladder cancer cells, as shown by the increased cleavage of caspase-3, an upregulated LC3-II/LC3-I ratio and the down-regulated p62 level. Blocking autophagy with 3-MA (3-Methyladenine) enhanced Fcn-induced apoptosis, indicating that Fcn-induced autophagy was adaptive. Additionally, we observed that Fcn treatment inhibited mTOR and reduced the intracellular ATP levels. The exogenous addition of methyl pyruvate (MP) to compensate metabolic substrates alleviated Fcn-induced apoptosis and autophagy. Conclusions: Our data indicated that Fcn caused an impairment in energy generation, which led to apoptosis and adaptive autophagy in bladder cancer. These results demonstrated that Fcn may be a potential candidate for use in the prevention and treatment of bladder cancer.
\end{abstract}

\section{Introduction}

(C) 2017 The Author(s)

Published by S. Karger AG, Basel

Bladder cancer is a urological malignant tumor that causes a heavy burden to patients and society. For advanced patients, combined chemotherapy is needed. However, resistance to chemotherapy drugs may gradually occur and significantly reduce the effects of treatment. Therefore, the discovery of novel low-toxicity drugs is beneficial for the prevention and treatment of the disease. 
Tetrandrine (Tet), a widely investigated compound, exhibits potent anti-tumor effects in lung cancer, prostate cancer, breast cancer and bladder cancer [1-6]. In bladder cancer, Tet induces apoptosis and reverses the epithelial-mesenchymal transition [2,6]. Tet and Fangchinoline (Fcn) are the two main bis-benzylisoquinoline alkaloids that exist in the plants of Stephania tetrandra. The structures of both Tet and Fcn are similar, but Fcn was reported to be associated with the inhibition of acetylcholinesterase and glutamate release in neurological diseases [7-9]. Fcn is a potent antioxidant, showing protective effects in oxidative cell injury [10]. This compound was also found to inhibit the growth of several cancers, such as lung cancer, breast cancer and prostate cancer, through proliferation inhibition and/or apoptosis [11-14] and induces autophagic cell death in hepatocellular cancer cells [15]. More recently, Fcn was found to block the well-known P-glycoprotein, indicating that Fcn may enhance the effects of chemotherapy drugs and prevents multidrug resistance [16]. However, whether Fcn can inhibit bladder cancer remains unclear. In the present study, we focused on the effects of Fcn on bladder cancer.

\section{Materials and Methods}

\section{Chemicals}

Fcn was purchased from Sigma-Aldrich (MO, USA), dissolved in DMSO to create an 80-mM stock solution and stored at $-80{ }^{\circ} \mathrm{C}$ for use. Z-VAD-FMK was obtained from Enzo Life Sciences (New York, USA). The mouse anti-PCNA antibody, 3-MA (3-Methyladenine) and Necrostatin-1 were purchased from Santa Cruz Biotechnology (Dallas, TX, USA). Methyl pyruvate (MP) was purchased from Acros (Geel, Belgium). The rabbit anti-LC3B antibody was purchased from Sigma-Aldrich. The rabbit anti-p62, rabbit anti-cleaved caspase-3, rabbit anti-caspase-3, rabbit anti-GAPDH, rabbit anti-p-4E-BP1, and rabbit anti-4E-BP1 primary antibodies and the goat anti-rabbit and anti-mouse HRP-tagged secondary antibodies were all purchased from Cell Signaling Technology (Boston, MA, USA).

\section{Cell culture}

Human bladder cancer T24 and 5637 cells were obtained from the Cell Resource Center of Shanghai Institutes for Biological Sciences (Chinese Academy of Sciences). The cells were cultured in RPMI-1640 medium (Thermo Fisher) with $10 \%$ (v/v) of fetal bovine serum (FBS) containing 100 units/ml penicillin and $0.1 \mathrm{mg} / \mathrm{ml}$ streptomycin in an atmosphere of $5 \% \mathrm{CO}_{2}$ at $37^{\circ} \mathrm{C}$.

\section{Proliferation measurement}

The proliferation of the cells was measured using a Cell Counting Kit-8 (CCK-8) assay. In brief, $1 \times$ $10^{4}$ cells/well were seeded into a 96-well plate. After the treatment, $10 \mu \mathrm{l} /$ well of CCK-8 reagent (Dojindo, Kumamoto, Japan) was added. The plate was then incubated at $37^{\circ} \mathrm{C}$ for $2 \mathrm{~h}$. The cell viability was measured as the relative optical density read at $450 \mathrm{~nm}$.

\section{Protein analysis}

The total protein from each group was extracted with RIPA lysis buffer, quantified, mixed with loading buffer for Western blotting, and heated to $100{ }^{\circ} \mathrm{C}$ for $5 \mathrm{~min}$. Then, $20 \mu \mathrm{g}$ of total protein in each group was loaded onto a SDS-PAGE gel. The protein samples were separated by electrophoresis and were blotted onto a nitrocellulose membrane. The membrane was then blocked with $5 \%$ non-fat milk for $1 \mathrm{~h}$ at room temperature. The membrane was then soaked in the corresponding primary antibodies at $4{ }^{\circ} \mathrm{C}$ overnight. The primary antibodies were diluted as 1:1000 in a Tris-buffered saline (TBS)/Tween solution (TBST). The membrane was then washed with TBST 4 times over 20 min. After that, the membrane was incubated with the goat anti-rabbit or goat anti-mouse HRP-tagged secondary antibody (1:2000) for $1 \mathrm{~h}$ at room temperature. The membrane was then washed with TBST 4 times over $20 \mathrm{~min}$. The bands were detected using a HRP substrate (Millipore, Bedford, MA, USA), and the band intensities were quantified using the Quantity One software V4.6.2 (Bio-Rad, CA, USA).

\section{KARGER}


ATP measurement

T24 and 5637 cells were seeded in a 96-well plate and treated with $5 \mu \mathrm{M}$ of Fcn for $24 \mathrm{~h}$. The levels of ATP were detected using the ATPlite luminescence assay system (PerkinElmer, Waltham, MA, USA) according to the manufacturer's protocol. In brief, the cells were lysed, and the relative ATP levels were reflected by the luminescence intensity in each group detected using a Varioskan 96-well plate reader (Thermo Fisher, Waltham, MA, USA).

\section{Statistical analysis}

All data in this study are presented as the mean \pm SD. A two-tailed Student's t-test or a one-way ANOVA was performed by using the SPSS 13.0 software (SPSS Inc., IL, USA). P $<0.05$ was considered statistically significant.

\section{Results}

\section{Fangchinoline inhibits bladder cancer proliferation}

To investigate whether Fcn exhibits anti-cancer effects in bladder cancer, T24 and 5637 cells were treated with a range of concentrations of Fen for 24, 48 and $72 \mathrm{~h}$. The cell viability was detected using a CCK-8 assay. We observed that the cell viabilities of both T24 and 5637 cells were significantly inhibited by Fcn $(\geq 5 \mu \mathrm{M})$ at 24,48 and $72 \mathrm{~h}(\mathrm{P}<0.01)$ in a dosedependent manner (Fig. 1A and 1B). The IC50 values of Fcn in T24 cells were $19.0 \mu \mathrm{M}$, (24

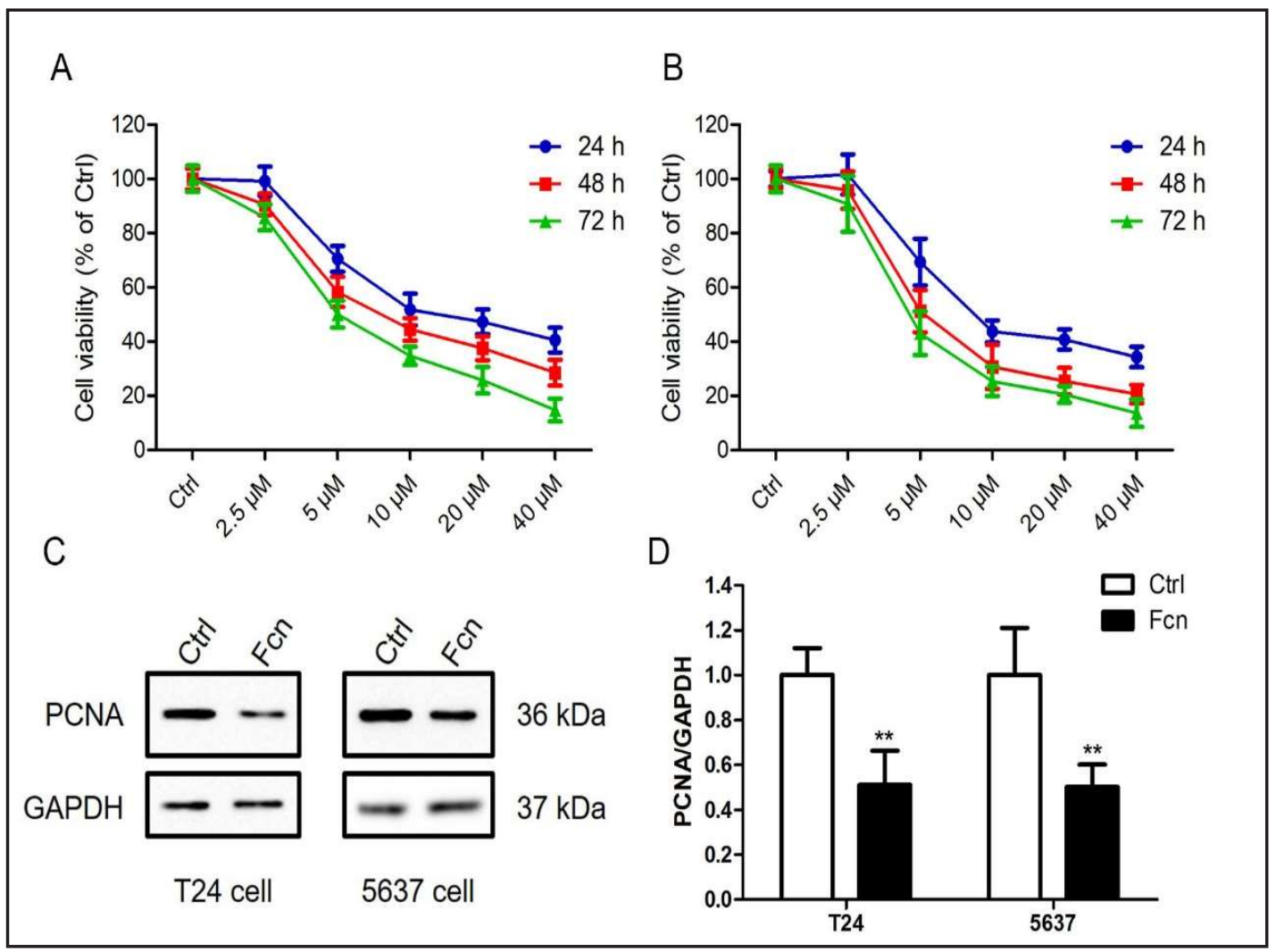

Fig. 1. Fangchinoline inhibits bladder cancer proliferation. (A, B) T24 (A) and 5637 (B) cells were treated with the indicated concentrations of Fangchinoline ( $F(n)$ for 24,48 and $72 \mathrm{~h}$, and the cell viability was detected using a CCK-8 assay. (C, D) T24 and 5637 cells were treated with $5 \mu \mathrm{M}$ Fcn for $24 \mathrm{~h}$. The expression of PCNA was detected using Western blotting (C). The densitometric analysis for the relative expression of PCNA was determined using the PCNA/GAPDH ratio (D). The data are expressed as the mean \pm SD; ${ }^{* *} \mathrm{P}<0.01$ compared with the control (Ctrl) group. 


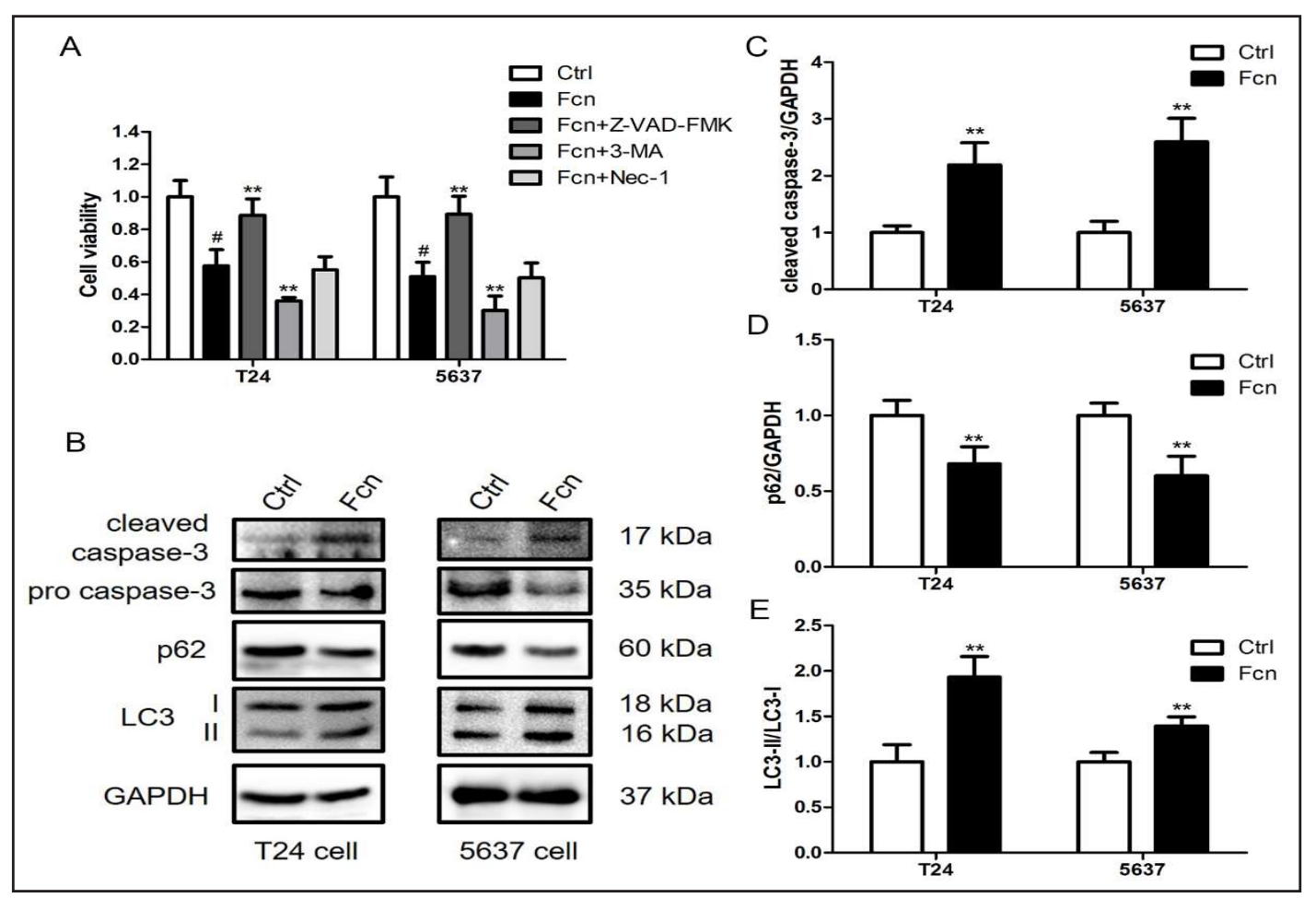

Fig. 2. Fangchinoline induces apoptosis and autophagy in bladder cancer cells. (A) T24 and 5637 cells were treated as indicated for $24 \mathrm{~h}$. The cell viability was detected using a CCK-8 assay. The data are expressed as the mean $\pm \mathrm{SD}$; ${ }^{* *} \mathrm{P}<0.01$ compared with the Fcn group and ${ }^{*} \mathrm{P}<0.01$ compared with the control (Ctrl) group. (B-E) T24 and 5637 cells were treated with $5 \mu \mathrm{M}$ of Fcn for $24 \mathrm{~h}$. The cleavage of caspase-3, the expression of p62 and the conversion of LC3 were detected using Western blotting (B). The densitometric analysis for the ratios of cleaved caspase-3/GAPDH (C), p62/GAPDH (D) and LC3-II/LC3-I (D) was measured. The data are expressed as the mean $\pm \mathrm{SD} ;{ }^{* *} \mathrm{P}<0.01$ compared with the control (Ctrl) group.

h), $12.0 \mu \mathrm{M}(48 \mathrm{~h})$ and $7.57 \mu \mathrm{M}(72 \mathrm{~h})$, and $11.9 \mu \mathrm{M}(24 \mathrm{~h}), 9.92 \mu \mathrm{M}(48 \mathrm{~h})$ and $7.13 \mu \mathrm{M}(72$ h) in 5637 cells.

We then detected the expression of proliferating cell nuclear antigen (PCNA) as a biomarker of proliferation. Consistent with the results from the CCK-8 assay, we found that the expression of PCNA was down-regulated in the two cell lines after Fcn treatment (Fig. $1 \mathrm{C}$ and 1D). These results indicated that Fcn was able to inhibit the proliferation of bladder cancer.

\section{Fangchinoline induces apoptosis and autophagy in bladder cancer}

To explore whether Fcn induces cell death, we treated the cells with $50 \mu \mathrm{M}$ of Z-VADFMK (apoptosis inhibitor), $30 \mu \mathrm{M}$ of Necrostatin-1 (necroptosis inhibitor) or $2 \mathrm{mM}$ of 3-MA (autophagy inhibitor) in combination with Fcn. The cell viability was then detected using a CCK-8 assay. We observed that Z-VAD-FMK partially rescued cell viability under treatment of Fcn. Additionally, 3-MA synergized the inhibitory effects of Fcn, but Necrostatin-1 did not alter the viability in the presence of Fcn (Fig. 2A).

We then detected the cleavage of caspase-3, a well-known biomarker of apoptosis. We observed that treating T24 and 5637 cells with Fcn caused a significant increase in the cleavage of caspase-3 (Fig. 2B and 2C). For autophagy, we detected the conversion of LC3 and the expression of p62. We found that Fcn induced a significant increase in the LC3-II/LC3-I ratio and a decrease in p62 in both T24 and 5637 cells (Fig. 2B, 2D and 2E). These results indicated that both apoptosis and autophagy were induced by Fcn in bladder cancer cells. 


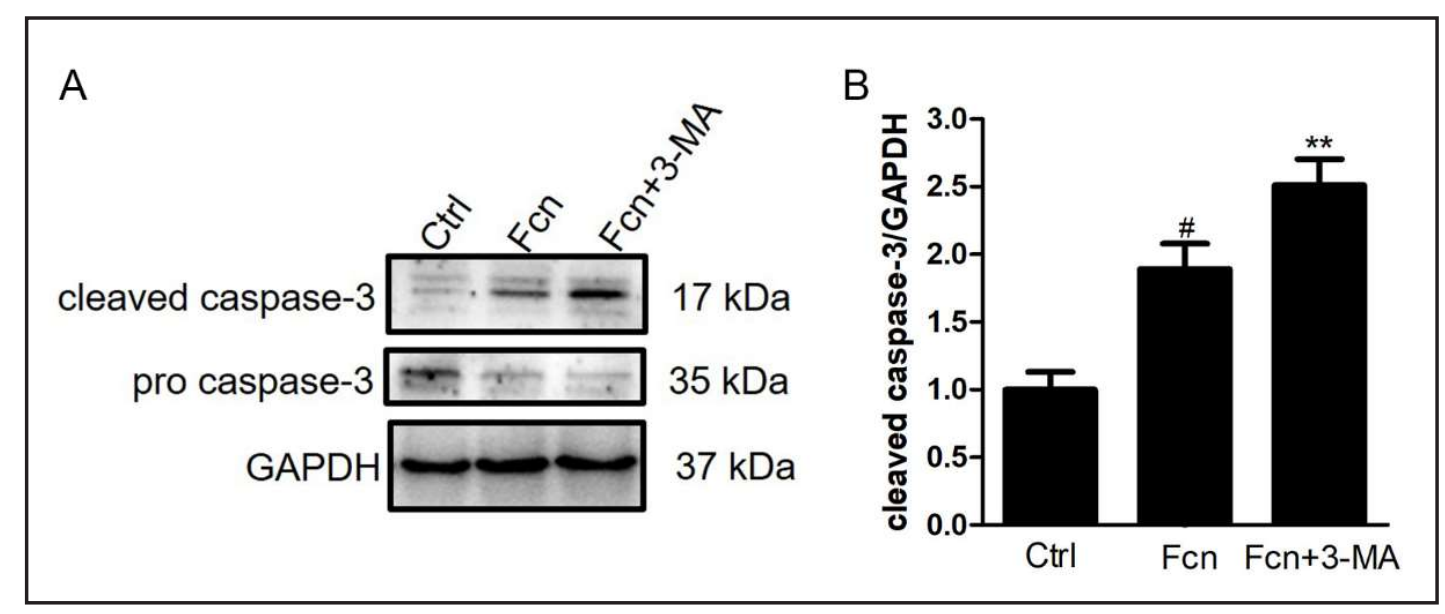

Fig. 3. Blunting autophagy enhances Fcn-induced apoptosis in bladder cancer cells. (A) T24 cells were treated with $5 \mu \mathrm{M}$ of Fangchinoline ( $\mathrm{Fcn}$ ) in the presence or absence of 3-MA ( $2 \mathrm{mM}$ ) or vehicle (as a control) for $24 \mathrm{~h}$. The cleavage of caspase-3 was detected using Western blotting. (B) The densitometric analysis for the ratios of cleaved caspase-3/GAPDH was measured. The data are expressed as the mean $\pm \mathrm{SD} ;{ }^{* * P}<0.01$ compared with the Fcn group and ${ }^{\#} \mathrm{P}<0.01$ compared with the control (Ctrl) group.

Inhibition of autophagy increased Fangchinoline-induced apoptosis

Autophagy is closely associated with the regulation of metabolism and cell survival control $[17,18]$. Blocking autophagy with 3-MA synergized the inhibitory effects of Fcn on bladder cancer cells (Fig. 2A). Therefore, we hypothesized that the activation of autophagy might be an adaptive response induced by Fcn. To investigate the role of autophagy in Fcn-induced cell death, we treated T24 cells with Fcn in the presence or absence of 3-MA. We observed that the cleavage of caspase-3 was enhanced by 3-MA (Fig. 3). These results indicated that the activation of autophagy might be an adaptive response in Fcn-treated bladder cancer cells, whereas the blockade of autophagy enhanced Fcn-induced cell death.

\section{Fangchinoline inhibited the mTOR pathway in bladder cancer}

The mTOR pathway is closely related to autophagy regulation. To clarify the mechanism of Fcn-induced autophagy activation, we detected the phosphorylation of 4E-BP1, a direct substrate of MTOR, in bladder cancer cells. T24 cells were treated with Fcn for 6, 12 and $24 \mathrm{~h}$. We observed that the phosphorylation of 4E-BP1 at the residues T37 and T46 was significantly inhibited (Fig. 4A and 4B), indicating that Fcn may induce autophagy through the inhibition of the mTOR pathway.

\section{Fangchinoline induces energetic impairment in bladder cancer}

The mTOR complexes play important roles in the regulation of nutrition and energy generation. The inhibition of mTOR induced by Fcn reflected a decrease in the metabolic substrates in bladder cancer cells. To verify whether the inhibitory effects of Fcn are associated with energy impairment, we detected the ATP levels after treatment with $5 \mu \mathrm{M}$ of Fcn for $24 \mathrm{~h}$. We observed that the relative ATP levels were significantly down-regulated in both T24 cells and 5637 cells (Fig. 4C). We then employed methyl pyruvate (MP) to compensate as a metabolic substrate for energy generation. MP could generate pyruvate acid, an important substrate for tricarboxylic acid cycle (TCA). In the presence of MP, the cell viability was increased after treatment with Fcn in both T24 and 5637 cells (Fig. 4D). Consistently, MP partially antagonized the Fcn-induced cleavage of caspase-3 in T24 cells (Fig. 4E and 4F). In addition, we observed that the addition of MP also reduced the ratio of LC3-II/LC3-I under the treatment of Fcn (Fig. 4E and 4F). These data indicated that the impairment of energy generation may contribute to Fcn-induced autophagy and apoptosis in bladder cancer. 


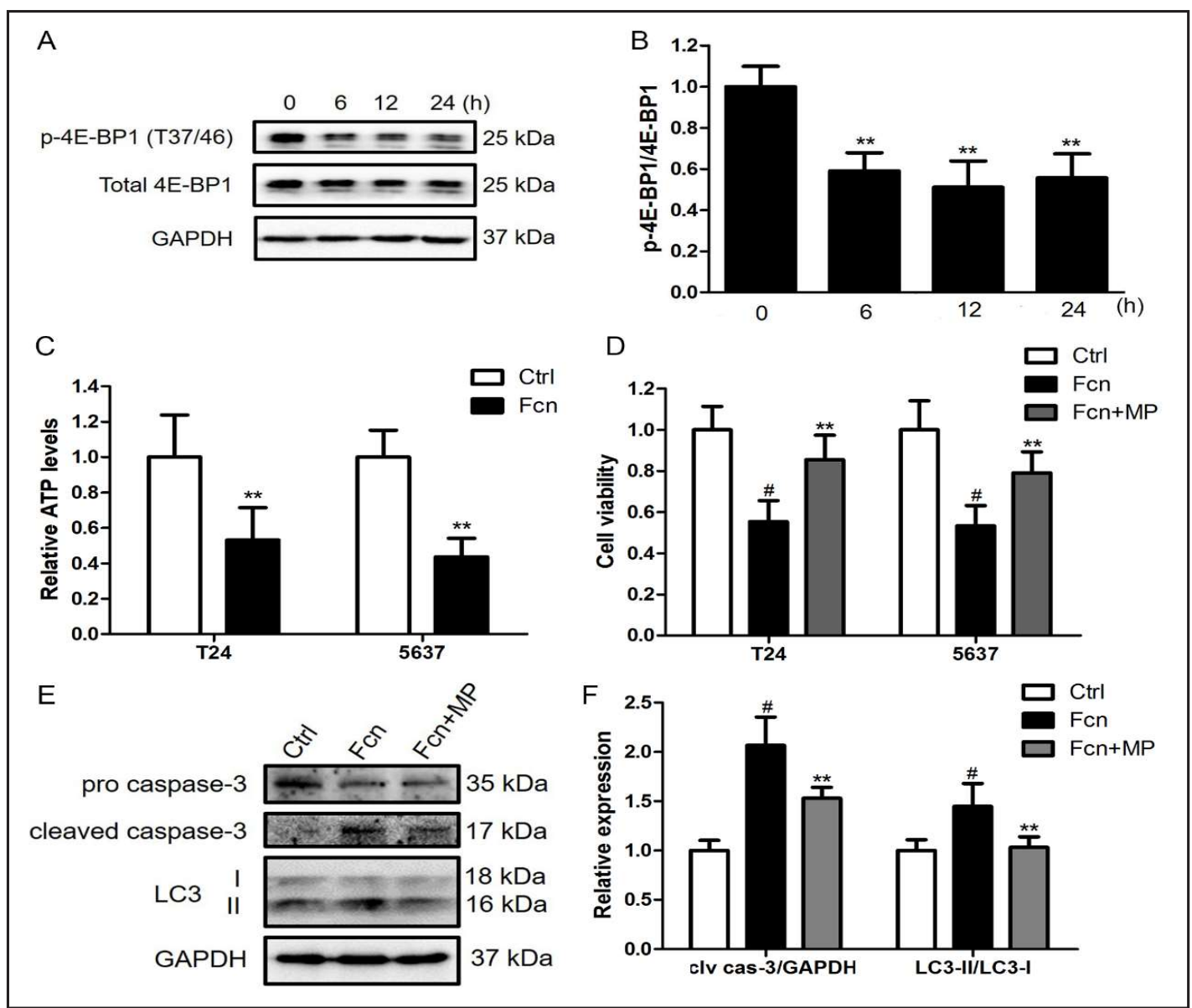

Fig. 4. Fangchinoline inhibits the mTOR pathway and induces energetic impairment in bladder cancer cells. (A, B) T24 cells were treated with $\mathrm{Fcn}(5 \mu \mathrm{M})$ for the indicated time. The phosphorylation levels of $4 \mathrm{E}-$ BP1 were detected (A), and the densitometric analysis for the p-4E-BP1/4E-BP1 ratios is shown (B) The data are expressed as the mean $\pm \mathrm{SD}$; ${ }^{* *} \mathrm{P}<0.01$ compared with the 0 h group. (C) T24 and 5637 cells were treated with $5 \mu \mathrm{M}$ of Fangchinoline (Fcn) for $24 \mathrm{~h}$. The relative ATP levels were measured. (D) T24 and 5637 cells were treated with $5 \mu \mathrm{M}$ of Fcn in the presence or absence of methyl pyruvate (MP; $2 \mathrm{mM}$ ) or vehicle (as a control) for $24 \mathrm{~h}$. The cell viability was detected using a CCK-8 assay. (E, F) T24 cells were treated as described as in (D). The cleavage of caspase- 3 and the conversion of LC3 were detected using Western blotting (E). The densitometric analysis for the ratios of cleaved caspase-3/GAPDH and LC3-II/LC3-I was determined (F). The data are expressed as the mean $\pm \mathrm{SD}$; ${ }^{* *} \mathrm{P}<0.01$ compared with the control (Ctrl) group (C) or the Fcn group (D, F), and ${ }^{\#} \mathrm{P}<0.01$ compared with the control (Ctrl) group (D, F).

\section{Discussion}

The present study highlights the anti-tumor effects that a natural product, Fcn, exhibits against bladder cancer. This compound could inhibit proliferation and induce apoptosis. For the first time, we revealed that Fcn induced protective autophagy in bladder cancer, inhibited the mTOR pathway, and thus eventually induced energetic impairment in bladder cancer. Our data indicated that Fcn is a potent anti-tumor compound that may be a potential candidate for the prevention and treatment of bladder cancer.

The anti-tumor effects of Fcn has been reported in many other cancers, such as lung cancer, prostate cancer, glioblastoma and breast cancer $[11-14,19,20]$. This compound 


\section{Cellular Physiology Cell Physiol Biochem 2017;43:1003-1011 \\ and Biochemistry Published online: October 02, $2017 \quad \begin{aligned} & \text { DO 2017 The Author(s). Published by S. Karger AG, Basel } \\ & \text { www.karger.com/cpb }\end{aligned}$ \\ Fan et al.: Fangchinoline Inhibits Bladder Cancer}

antagonizes multidrug resistance-related drugs by targeting P-glycoprotein, which may improve drug resistance in chemotherapy [21]. Fcn targets the PI3K/Akt/GSK-3 $\beta$ pathway and induces apoptosis [13]. Fcn can also modulate cell cycle-related proteins, such as PCNA, p27 and cyclin D, and thus induces G1/S arrest in prostate cancer [20]. In the present study, we investigated the effects of Fcn on two widely used bladder cancer cell lines, T24 and 5637 cells. Notably, 5637 cells may have lower chemotherapy resistance than T24 cells [22]. We observed that Fcn inhibited proliferation and activated apoptosis in bladder cancer. Fcn treatment resulted in the cleavage of caspase-3, whereas blocking caspase activation with Z-VAD-FMK antagonized Fcn-induced cell death. These results indicated that Fcn-induced caspase-dependent apoptosis in bladder cancer. However, these effects were similar in the two cell lines.

Autophagy is an important process that regulates cell survival, metabolism and energy generation [23]. The activation of autophagy induced by stimulants may be adaptive or maladaptive [24]. It has been reported that Fcn can induce autophagic cell death in hepatocellular carcinoma cells, indicating the presence of a Fcn-induced maladaptive response in these cells [15]. This effect is associated with the p53/sestrin2/AMPK signaling pathway [15]. We observed that Fcn could also significantly activate autophagy in bladder cancer cells, as shown by the increased LC3-II/LC3-I ratios and decreased p62 levels. However, our data indicated that the activation of autophagy in bladder cancer induced by Fcn was an adaptive response, whereas the blockade of autophagy enhanced Fcn-induced cell death. The appropriate activation of autophagy always plays a protective role in response to harmful irritation, such as stress injury and energy depletion [23, 25-27]. The activation of autophagy could sequester protein aggresomes and injured organelles to limit the injury $[28,29]$. The cargoes in the autophagosomes are degraded, and the products were released as substrates of metabolism $[28,29]$. However, the excessive activation of autophagy may induce cell death. Our results indicated that the autophagy induced by Fcn in bladder cancer cells was protective rather than a process leading to cell death. These data indicated that Fcn-induced autophagy may play multiple roles according to the context of the cancer.

The mTOR signaling pathway is one of the key pathways that control the autophagy level [30]. Our data revealed that Fcn significantly inhibited the mTOR pathway. Additionally, mTOR also plays an important role in controlling intracellular nutrition, and it could be inhibited during the nutrition depletion [31,32]. In the present study, we observed that Fcn caused a decrease in the ATP level, whereas the exogenous supplement of tricarboxylic acid cycle substrates partially antagonized Fcn-induced apoptosis and autophagy. On the one hand, these results support that the Fcn-induced apoptosis was due to energetic impairment, possibly through the mTOR pathway. On the other hand, the inhibition of MTOR induced by Fcn activated autophagy, which could up-regulate the degradation of intracellular components to generate metabolic substrates for the compensation of energetic depletion stress. This mechanism may explain why blocking this adaptive autophagy led to increased cell death.

Many natural products show anti-tumor effects in bladder cancer [33]. The present study indicated that Fcn, an anti-tumor compound, inhibited bladder cancer. Our data supports Fcn as a potential candidate for the prevention and treatment of bladder cancer.

\section{Acknowledgements}

We thank Dr. Yongqing Shen at the Hebei University of Chinese Medicine for the advice on our autophagy investigation.

\section{Disclosure Statement}

The authors declare no competing financial interests.

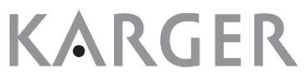




\section{Cellular Physiology Cell Physiol Biochem 2017;43:1003-1011 \begin{tabular}{l|l} 
and Biochemistry Published online: October 02, 2017 & $\begin{array}{l}\text { C) } 2017 \text { The Author(s). Published by S. Karger AG, Basel } \\
\text { www.karger.com/cpb }\end{array}$ \\
\hline
\end{tabular}}

\section{References}

1 Qiu W, Zhang AL, Tian Y: Tetrandrine triggers an alternative autophagy in du145 cells. Oncol Lett 2017;13:3734-3738.

-2 Zhang Y, Liu W, He W, Zhang Y, Deng X, Ma Y, Zeng J, Kou B: Tetrandrine reverses epithelial-mesenchymal transition in bladder cancer by downregulating Gli-1. Int J Oncol 2016;48:2035-2042.

- 3 Lin Y, Wang Y, Liu X, Yan J, Su L, Liu X: A novel derivative of tetrandrine (H1) induces endoplasmic reticulum stress-mediated apoptosis and prosurvival autophagy in human non-small cell lung cancer cells. Tumour Biol 2016;37:10403-10413.

-4 Qiu W, Su M, Xie F, Ai J, Ren Y, Zhang J, Guan R, He W, Gong Y, Guo Y: Tetrandrine blocks autophagic flux and induces apoptosis via energetic impairment in cancer cells. Cell Death Dis 2014;5:e1123.

5 Xu W, Debeb BG, Lacerda L, Li J, Woodward WA: Tetrandrine, a compound common in chinese traditional medicine, preferentially kills breast cancer tumor initiating cells (TICs) in vitro. Cancers (Basel) 2011;3:2274-2285.

6 Li X, Su B, Liu R, Wu D, He D: Tetrandrine induces apoptosis and triggers caspase cascade in human bladder cancer cells. J Surg Res 2011;166:e45-51.

7 Li D, Liu H, Liu Y, Zhang Q, Liu C, Zhao S, Jiao B: Design, synthesis and biological activities of tetrandrine and fangchinoline derivatives as antitumer agents. Bioorg Med Chem Lett 2017;27:533-536.

-8 Lin TY, Lu CW, Tien LT, Chuang SH, Wang YR, Chang WH, Wang SJ: Fangchinoline inhibits glutamate release from rat cerebral cortex nerve terminals (synaptosomes). Neurochem Int 2009;54:506-512.

-9 Markmee S, Ruchirawat S, Prachyawarakorn V, Ingkaninan K, Khorana N: Isoquinoline derivatives as potential acetylcholinesterase inhibitors. Bioorg Med Chem Lett 2006;16:2170-2172.

$>10$ Koh SB, Ban JY, Lee BY, Seong YH: Protective effects of fangchinoline and tetrandrine on hydrogen peroxideinduced oxidative neuronal cell damage in cultured rat cerebellar granule cells. Planta Med 2003;69:506512.

-11 Luo X, Peng JM, Su LD, Wang DY, Yu YJ: Fangchinoline inhibits the proliferation of spc-a-1 lung cancer cells by blocking cell cycle progression. Exp Ther Med 2016;11:613-618.

12 Li D, Lu Y, Sun P, Feng LX, Liu M, Hu LH, Wu WY, Jiang BH, Yang M, Qu XB, Guo DA, Liu X: Inhibition on proteasome $\beta 1$ subunit might contribute to the anti-cancer effects of fangchinoline in human prostate cancer cells. PLoS one 2015;10:e0141681.

13 Wang CD, Yuan CF, Bu YQ, Wu XM, Wan JY, Zhang L, Hu N, Liu XJ, Zu Y, Liu GL, Song FZ: Fangchinoline inhibits cell proliferation via Akt/GSK-3beta/ cyclin D1 signaling and induces apoptosis in MDA-MB-231 breast cancer cells. Asian Pac J Cancer Prev 2014;15:769-773.

14 Xing Z, Zhang Y, Zhang X, Yang Y, Ma Y, Pang D: Fangchinoline induces G1 arrest in breast cancer cells through cell-cycle regulation. Phytother Res 2013;27:1790-1794.

15 Wang N, Pan W, Zhu M, Zhang M, Hao X, Liang G, Feng Y: Fangchinoline induces autophagic cell death via p53/sestrin2/AMPK signalling in human hepatocellular carcinoma cells. Br J Pharmacol 2011;164:731742 .

16 Sun YF, Wink M: Tetrandrine and fangchinoline, bisbenzylisoquinoline alkaloids from Stephania tetrandra can reverse multidrug resistance by inhibiting P-glycoprotein activity in multidrug resistant human cancer cells. Phytomedicine 2014;21:1110-1119.

17 Xiao Y, Deng Y, Yuan F, Xia T, Liu H, Li Z, Chen S, Liu Z, Ying H, Liu Y, Zhai Q, Guo F: An ATF4-ATG5 signaling in hypothalamic POMC neurons regulates obesity. Autophagy 2017;13:1088-1089.

$>18$ Swart C, Du Toit A, Loos B: Autophagy and the invisible line between life and death. Eur J Cell Biol 2016;95:598-610.

19 Guo B, Xie P, Su J, Zhang T, Li X, Liang G: Fangchinoline suppresses the growth and invasion of human glioblastoma cells by inhibiting the kinase activity of Akt and Akt-mediated signaling cascades. Tumour Biol 2016;37:2709-2719.

20 Wang CD, Huang JG, Gao X, Li Y, Zhou SY, Yan X, Zou A, Chang JL, Wang YS, Yang GX, He GY: Fangchinoline induced G1/S arrest by modulating expression of p27, PCNA, and cyclin D in human prostate carcinoma cancer PC3 cells and tumor xenograft. Biosci Biotechnol Biochem 2010;74:488-493.

-21 Choi SU, Park SH, Kim KH, Choi EJ, Kim S, Park WK, Zhang YH, Kim HS, Jung NP, Lee CO: The bisbenzylisoquinoline alkaloids, tetrandine and fangchinoline, enhance the cytotoxicity of multidrug resistance-related drugs via modulation of P-glycoprotein. Anticancer Drugs 1998;9:255-261. 


\section{Cellular Physiology Cell Physiol Biochem 2017;43:1003-1011

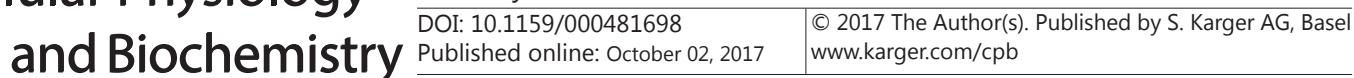

Fan et al.: Fangchinoline Inhibits Bladder Cancer

-22 Xu X, Wang X, Fu B, Meng L, Lang B: Differentially expressed genes and microRNAs in bladder carcinoma cell line 5637 and T24 detected by RNA sequencing. Int J Clin Exp Pathol 2015;8:12678-12687.

23 Guo JY, White E: Autophagy, metabolism, and cancer. Cold Spring Harb Symp Quant Biol 2016;81:73-78.

24 Ryter SW, Cloonan SM, Choi AM: Autophagy: a critical regulator of cellular metabolism and homeostasis. Mol Cells 2013;36:7-16.

25 Delbridge LMD, Mellor KM, Taylor DJ, Gottlieb RA: Myocardial stress and autophagy: mechanisms and potential therapies. Nat Rev Cardiol 2017;14:412-425.

-26 Tang Y, Li J, Li F, Hu CA, Liao P, Tan K, Xiong X, Liu G, Li T, Yin Y: Autophagy protects intestinal epithelial cells against deoxynivalenol toxicity by alleviating oxidative stress via IKK signaling pathway. Free Radic Biol Med 2015;89:944-951.

27 Mukhopadhyay S, Das DN, Panda PK, Sinha N, Naik PP, Bissoyi A, Pramanik K, Bhutia SK: Autophagy protein Ulk1 promotes mitochondrial apoptosis through reactive oxygen species. Free Radic Biol Med 2015;89:311-321.

28 Christian F, Anthony DF, Vadrevu S, Riddell T, Day JP, McLeod R, Adams DR, Baillie GS, Houslay MD: p62 (SQSTM1) and cyclic AMP phosphodiesterase-4a4 (PDE4A4) locate to a novel, reversible protein aggregate with links to autophagy and proteasome degradation pathways. Cell Signal 2010;22:1576-1596.

29 Olzmann JA, Chin LS: Parkin-mediated K63-linked polyubiquitination: A signal for targeting misfolded proteins to the aggresome-autophagy pathway. Autophagy 2008;4:85-87.

-30 Ravikumar B, Vacher C, Berger Z, Davies JE, Luo S, Oroz LG, Scaravilli F, Easton DF, Duden R, O’Kane CJ, Rubinsztein DC: Inhibition of mTOR induces autophagy and reduces toxicity of polyglutamine expansions in fly and mouse models of Huntington disease. Nat Genet 2004;36:585-595.

-31 Cheng CW, Villani V, Buono R, Wei M, Kumar S, Yilmaz OH, Cohen P, Sneddon JB, Perin L, Longo VD: Fastingmimicking diet promotes Ngn3-driven $\beta$-cell regeneration to reverse diabetes. Cell 2017;168:775-788 e712.

-32 Sato T, Umetsu A, Tamanoi F: Characterization of the rheb-mTOR signaling pathway in mammalian cells: constitutive active mutants of Rheb and mTOR. Methods Enzymol 2008;438:307-320.

33 Zhi Y, Pan J, Shen W, He P, Zheng J, Zhou X, Lu G, Chen Z, Zhou Z: Ginkgolide B Inhibits human bladder cancer cell migration and invasion through microRNA-223-3p. Cell Physiol Biochem 2016;39:1787-1794. 